\title{
O público e o privado Para os serviços sociais ${ }^{1}$
}

\author{
LiAnE VizZotTo* \\ Berenice Corcetti* \\ SANDRA PIEROZAN ${ }^{* * *}$
}

\begin{abstract}
RESUMO: O tema desta reflexão é a regulação jurídica na relação público-privada. O objetivo é analisar os instrumentos jurídicos utilizados em parcerias, demonstrando como elas ocorrem no contexto dos serviços sociais, inclusive na educação. A consulta à legislação e à literatura são as fontes de pesquisa. Há o crescimento dos instrumentos reguladores decorrente de leis criadas para regulação das parcerias, tornando-os fundamentais na legalização das políticas educacionais. A terceirização dos serviços educacionais é legitimada pela relação público-privada.
\end{abstract}

Palavras-chave: Relação público-privada. Instrumentos jurídicos. Serviços sociais. Educação.

\section{The public and the private}

\section{For social services}

\begin{abstract}
The theme of this reflection is the legal regulation of public-private relations. The objective is to analyze the legal instruments used in partnerships, demonstrating how they occur in
\end{abstract}

* É Mestre em Educação pela Universidade Federal do Paraná. Atua como professora nos cursos de especialização PROEJA e Educação do Campo. É professora no IFC-Campus Concórdia nas disciplinas de Políticas Educacionais, Educação Inclusiva, Fundamentos Teóricos e Metodológicos, Estágio e Psicologia da Educação. Concórdia, SC- Brasil. Email: <liane.vizzotto@ifc.edu.br>.

** Possui mestrado em História pela Universidade Federal Fluminense e é Doutora em Educação pela Universidade Estadual de Campinas. É bolsista de Produtividade em Pesquisa do CNPq. Atualmente é professora da Universidade do Vale do Rio dos Sinos, integrando o corpo docente permanente do Programa de Pós-Graduação em Educação. São Leopoldo, RS- Brasil. E-mail: <cor7@terra.com.br>.

** É Mestre em Educação pela Universidade Federal do Paraná. Atualmente é professora da Universidade Federal da Fronteira Sul (UFFS) - Campus Erechim e doutoranda em Educação na Universidade do Vale do Rio dos Sinos. Erechim, RS- Brasil. E-mail: <sandra.pierozan@uffs.edu.br>. 
the context of social services, including in education. Consultation of legislation and literature are the sources for our research. There has been a growth in regulatory instruments stemming from laws created to regulate partnerships, making them fundamental in the legalization of educational policies. Outsourcing of educational services is legitimized by the public-private relationship.

Keywords: Public-private relationship. Legal instruments. Social services. Education.

\section{Lo público y lo privado}

Para los servicios sociales

RESUMEN: El tema de esta reflexión es la regulación jurídica en la relación público-privado. El objetivo es analizar los instrumentos jurídicos utilizados en las alianzas, demostrando cómo estas ocurren en el contexto de los servicios sociales, incluyendo la educación. La legislación y la literatura son las fuentes de la investigación. Hay un aumento de los instrumentos reguladores resultante de leyes creadas para regular las alianzas y que los hace fundamentales para la legalización de las políticas educativas. La relación público-privado legitima la externalización de los servicios educativos.

Palabras clave: Relación público-privado. Instrumentos jurídicos. Servicios sociales. Educación.

\section{Le public et le privé}

Pour les services sociaux

RÉSUMÉ: Le thème de cet article est la régulation mégale dans les relations public-privé. Le but est d'analyser les instruments juridiques utilisés dans les partenariats, en montrant comment ils se produisent dans me contexte des services sociaux, y compris dans l'éducation. Cette recherche s'appuie sur une consultation de la législation et de la littérature. On constate une augmentation des instruments régulateurs issus des lois créées pour la régulation des partenariats, les rendants fondamentaux dans la législation des politiques 
éducatives. La tercerisation des services éducatifs est légitimée par la relation public-privé.

Mots-clés: Relation public-privé. Instruments juridiques. Services sociaux. Éducation.

\section{Introdução}

relação público-privada tem sido pauta atual de debate, devido ao espaço 4 que está tomando no âmbito da definição das políticas estatais, bem como 11 pelo sentido que tem e pela amplitude de suas implicações para os serviços sociais. No caso da educação, os limites colocados por essas políticas no direito e na democratização da educação ensejam preocupações de pesquisas (ADRIÃO, 2015; ADRIÃO, PERONI, 2011), na medida em que o direcionamento do conteúdo e a execução das políticas educacionais passam a ser definidos por sociedades empresariais, institutos ou fundações, cujos marcos ideológicos ultrapassam o interesse comum, para introduzir preceitos do mercado. Portanto, os serviços educacionais assumem conceitos das relações de produção mercadológicas, as quais se inserem como premissas básicas de eficiência na Nova Gestão Pública (NGP).

A estruturação da NGP não seria possível sem um aparato jurídico. Fundamentos legais foram construídos a partir das mudanças decorrentes nas funções do Estado, especialmente nos anos de 1990 e com alterações na Constituição Federal (CF) brasileira. É sobre essa questão que desejamos refletir. Logo, se constitui objetivo deste trabalho analisar os instrumentos jurídicos utilizados nas parcerias, demonstrando como elas ocorrem entre a esfera pública estatal e o setor privado, no contexto dos serviços sociais, em especial, na educação.

Os interesses privados sempre se sobressaíram aos públicos no decorrer da história da educação brasileira, mesmo em períodos anteriores às reformas do aparelho do $E s_{a d o}{ }^{2}$ na década de 1990. O Estado subvencionou a educação privada por meio de bolsas de estudos, isenção fiscal, dentre outros mecanismos de ações governamentais, deixando, muitas vezes, de construir políticas públicas educacionais, tanto na educação básica quanto na superior. A omissão possibilitou a consolidação do interesse privado, fosse pelo domínio da Igreja ou de outros grupos privatistas, especialmente em nome da liberdade de ensino (LOMBARDI, JACOMELI e SILVA, 2005).

Nesta reflexão, ocupamo-nos de documentos contidos em sites públicos oficiais e da literatura que discute a relação público-privada. Entendemos necessária a construção dessa análise a partir da legislação, haja vista as constantes aprovações e alterações de leis que amparam as parcerias entre a administração pública e o setor privado. Este 
último, constituído por instituições não estatais e por empresas lucrativas, é comumente chamado e aclamado pelo discurso neoliberal para dar suporte às políticas públicas, pois se acredita que a participação da sociedade civil na gestão pública (governança) a torne mais eficiente e qualificada. Frente a isso, o aparato jurídico é realmente uma ferramenta que legitima os processos.

Temos clareza de que a relação público-privada como simples regulação deixa de lado a verdadeira essência das normas. Numa perspectiva histórica, as normas jurídicas regulam diferentes esferas da totalidade social também inscritas no campo educacional. Não podem, de modo algum, ser analisadas fora do movimento do real, o qual, nesse momento histórico, configura-se pela consolidação de uma estrutura reguladora do mercado sobre os direitos sociais.

Para responder ao objetivo, essa reflexão está organizada em duas seções. Na primeira, apresentamos aspectos históricos que foram fundamentais à regulação jurídica existente no que diz respeito às parcerias, especialmente transitando pela reforma do aparelho do Estado e nos fundamentos da NGP, marcada pela governança e pela eficiência. Procuramos evidenciar os elementos da reforma, aproximando-nos do campo da educação, foco maior desta reflexão.

Num segundo momento, partimos dos instrumentos jurídicos para demonstrar como podem ser reguladas as parcerias entre os setores público e privado, ou seja, como elas ocorrem na relação público-privada.

\section{A relação público-privada na educação}

A relação entre o público e o privado na educação se constitui em um conflito histórico, visto ser matéria de debate em diferentes grupos e classes sociais.

Em âmbito global, nos anos de 1980, quando o ideário neoliberal ganhou força, houve a fragmentação das políticas estatais protecionistas, favorecendo a livre movimentação do comércio, das finanças e do trabalho, a privatização de uma série de atividades até então estatais e a implantação de políticas de concorrência entre os setores público e privado, provocando mudanças no cenário até então conhecido. Essas variações fizeram com que o Estado fosse reestruturado em três principais objetivos, a saber: servir aos interesses dos negócios; remodelar as suas operações internas com base nos negócios; e reduzir a exposição do governo à pressão política do eleitorado. A partir dessa reestruturação, os propósitos foram traduzidos em novos discursos e estratégias de gestão, fazendo surgir a Nova Gestão Pública (ROBERTSON; VERGER, 2012, p. 1136), designada 
No Brasil, os movimentos da reforma começam a aparecer em 1980 e concretizaram-se no Plano Diretor da Reforma do Aparelho do Estado, em 1995 (DI PIETRO, 2015). As características básicas do novo campo semântico construído com a reforma estatal vão ao encontro de uma NGP.

O modelo de gestão que se instala, principalmente a partir do Governo Fernando Henrique Cardoso, inclui a descentralização das políticas sociais para os municípios, bem como para setores do mercado, por meio do envolvimento de organizações da iniciativa privada na gestão pública (LUZ, 2013).

O texto da CF de 1988 antecipava as mudanças que vieram na década de 1990, decorrentes do modelo político vigente no País. Nela, já se observava a presença dos ideais de colaboração entre os setores público e privado, afinal a Constituição permite "[...] o repasse de recursos públicos a entidades privadas de natureza comunitária, confessional ou filantrópica, desde que comprovem finalidades não lucrativas [...]" (DI PIETRO, 2015, p. 28).

O período da NGP, cujas mudanças na administração pública aludem à ineficiência do Estado e à veiculação em nível internacional de discursos reformistas, é fortalecido com propostas de privatização dos serviços sociais públicos, inclusive por orientação de organismos multilaterais.

A reforma no Brasil, orientada pela eficiência e a qualidade, implicou na maior participação do cidadão e das entidades privadas na administração pública. A partir desses aspectos, o foco passa a ser o interesse público ${ }^{3}$ e o cidadão se torna o principal beneficiário dos recursos estatais. (DI PIETRO, 2015).

As estratégias estabelecidas pela reforma se diferenciam para cada setor de serviços públicos, sendo que nos sociais reconhece-se a atuação essencial do Estado, mas podem conviver com a iniciativa privada, ou seja, "nos serviços não-exclusivos (sic), a administração deve ser mais que descentralizada - deve ser autônoma: a sociedade civil dividirá, com o governo, as tarefas de controle" (BRESSER-PERREIRA, 1997, p. 35).

Importante notar que, na reforma, os argumentos se justificam pela orientação da administração gerencial, sendo que a principal ideia é a descentralização e a delegação de autoridade. Por isso, para cada setor é necessário definir como o Estado opera, ou seja, definir que tipo de administração, que tipo de propriedade e que tipo de instituição. A administração é a gerencial e, no núcleo estratégico, há que se considerar a efetividade em detrimento à eficiência, sendo esta o fim dos demais setores (BRESSER-PERREIRA, 1997).

Quanto à propriedade, nos serviços não exclusivos, sua definição é considerada mais complexa. 


\begin{abstract}
Se assumirmos que devem ser financiadas ou fomentadas pelo Estado, seja porque envolvem direitos humanos básicos (educação, saúde) seja porque implicam exteriormente envolvendo economias que o mercado não pode compensar na forma de preço e lucro (educação, saúde, cultura, pesquisa científica), não há razão para que sejam privatizados. Por outro lado, uma vez que não implicam no exercício do poder do Estado, não há razão para que sejam controlados pelo Estado. Se não têm, necessariamente, de ser propriedade do Estado nem de ser propriedade privada, a alternativa a adotar-se o regime de propriedade pública não-estatal (sic) [...]. "Pública" no sentido de se dedicar ao interesse público, que deve ser de todos, para todos, que não visa ao lucro; "não-estatal (sic)" porque não é parte do aparelho do Estado (BRESSER-PEREIRA, 1997, p. 35, destaques do original).
\end{abstract}

Os idealizadores da reforma encontraram um meio de justificar a necessidade de envolver as instituições não estatais na condução das políticas educacionais, ou seja, a educação não é apenas estatal, tanto quanto não se apresenta apenas privada (a não ser quando oferecida pelo setor privado). A explicação encontrada avança na direção de delegar para o Terceiro Setor a educação pública, num modelo descentralizado, tanto do ponto de vista da municipalização, que se consolida ao final dos anos de 1990, quanto da participação da sociedade.

Segundo Bresser-Pereira (1997), a combinação entre o Estado subsidiador/financiador e a gestão gerencial é a mais adequada e, por isso, as organizações públicas não estatais são bem-vindas ao novo modelo. Não se deseja nem um Estado produtor (burocrata), nem apenas regulador (neoliberal). O modelo proposto e adequado pela reforma se aproxima da tendência socialmente moderna, que tem como principal pressuposto a descentralização. Tanto nas atividades exclusivas como nos serviços não exclusivos, o contrato de gestão é o instrumento que o núcleo estratégico (centro definidor das leis) usará para o controle.

Nesse contexto, a educação é situada nas atividades exclusivas e nos serviços não exclusivos, pois, na primeira, o Estado aparece como subsidiário da educação básica, e nos serviços não exclusivos ele é o responsável último pela educação, mesmo que a descentralização por colaboração seja comum e até mesmo recomendável (LUZ, 2013).

Nos critérios exigidos pela NGP encontram-se a eficiência, a competição administrativa e a avaliação de desempenho (LUZ, 2013). Com a proposição de adequação das políticas sociais, o Estado garantiu a ampliação da atuação do setor privado na educação, seja para financiar a escola privada, seja para manter sua a escola pública com a participação da sociedade civil, muito embora legalizando uma reforma que mudou e continua a mudar a educação.

Após a Reforma do Aparelho do Estado, o governo federal propôs uma série de leis que possibilitaram concretizar as intenções da reforma. Ainda hoje vemos que as parcerias entre o setor público e o privado crescem em nome da boa governança e da democratização dos serviços sociais, especialmente da educação. 


\section{Instrumentos que possibilitam as parcerias}

A Emenda Constitucional no 19/1998 fez várias previsões voltadas para a consecução dos objetivos da reforma na administração pública, legitimando o diálogo entre os setores público e privado. Decorrente dessas alterações, muitas das legislações podem ser aplicadas no campo da educação na relação público-privada. ${ }^{4}$

De modo geral, parceria é o termo "utilizado para designar todas as formas de sociedade que, sem formar uma nova pessoa jurídica, são organizadas entre os setores público e privado, para consecução de fins de interesse público" (DI PIETRO, 2015, p. 24). Para tanto, são necessários instrumentos de parceria, os quais estão previstos no direito brasileiro: concessão e permissão de serviços públicos; concessão de obra pública; concessão patrocinada e concessão administrativa (essas duas englobadas sob o título de Parceria Público-Privada - Lei nº. 11.079/2004); contrato de gestão [parceria com organizações sociais (OS)]; termo de parceria com as organizações da sociedade civil de interesse público (Oscip); convênios, consórcios e outros ajustes referidos no artigo 116 da Lei no 8.666/1993 (DI PIETRO, 2015).

As parcerias na administração pública dependem do tipo de atividade administrativa e

Para os serviços sociais o Plano Diretor previu os contratos de gestão com as OS com base na Lei 9.637/98; também é possível o termo de parceria com as organizações da sociedade civil de interesse público (OSCIPS), conforme previsto na Lei n. 9.790/99; além disso, é cabível a concessão administrativa referida pela Lei n. 11.079/2004, bem como a terceirização dos serviços que se enquadrem nos art. $6^{\circ}$, II e da 13 da Lei n. 8.666 [...] (DI PIETRO, 2015, p. 43).

Os instrumentos - contratos de gestão, termos de parceria, concessão administrativa e terceirização, bem como os criados com a Lei nํㅗ 13.019/2014 - termos de colaboração e fomento, caracterizam-se como formas de consolidar a parceria entre os setores públicos e privados nos serviços sociais.

Tais instrumentos podem ser utilizados em diferentes situações da relação público-privada e possuem características específicas. Passamos a analisá-los.

Os contratos de gestão são efetivados a partir de parcerias entre organizações sociais (OS) e a administração pública. Servem para estabelecer um vínculo jurídico entre ambos. A Lei n 9.648/1998 que alterou a lei de licitações e contratos, " privilegiou as organizações sociais ao prever, entre as hipóteses de dispensa de licitação, a celebração de contratos de prestação de serviços com as organizações sociais [...]" (DI PIETRO, 2015, p. 279).

No entanto, é possível que a gestão pública proceda à transferência de recursos financeiros às OS, tanto como é possível à efetivação da parceria sem a transferência,

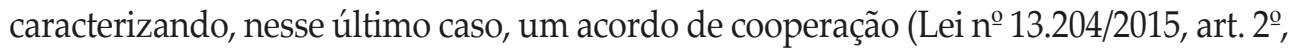


letra c, inciso VIII-A). Nas situações que envolvem recursos, os instrumentos legitimadores da parceria são o termo de colaboração e o termo de fomento, conforme prevê art. $2^{\underline{ }}$, letra c, incisos VII e VIII da Lei no 13.204/2015. Na efetivação da parceria, é necessário que o Poder Público, por meio de comissão de seleção faça um chamamento público, previsto no art. $2^{\circ}$, letra c, inciso $\mathrm{X}$.

A aprovação da Lei nº 13.019/2014 com redação alterada pela Lei nº 13.204 de 14 de dezembro de 2015 estabeleceu o regime jurídico das parcerias entre a administração pública e as organizações da sociedade civil (Marco Regulatório das Organizações da Sociedade Civil).

Importante notar que a Lei n⿳0 9.637/1998 qualifica as entidades como OS, estabelecendo os requisitos para tal, enquanto que as Leis no 13.019/2014 e 13.204/2015 definem o regime, ou seja, como podem ser celebradas as parcerias entre as OS e o setor público. As organizações sociais de que tratam as duas últimas leis dizem respeito às instituições sem fins lucrativos para prestação de serviços de interesse público, em regime de mútua colaboração e abrangem todas as organizações da sociedade civil (gênero) e suas diversas espécies: Oscip, OS, associações cooperativas e organizações religiosas.

A importância atribuída à criação de leis que consolidam a participação da sociedade civil na gestão pública, inclusive podendo ser aplicadas na educação, reforça os preceitos da reforma, agora num novo momento histórico, cujo protagonismo de instituições privadas tem sido destacado no desenvolvimento das políticas educacionais.

E essas leis não são apenas de abrangência federal, mas podem ser encontradas em âmbito municipal, a exemplo do projeto de lei $^{5}$ que visa institucionalizar a concepção educativa das competências socioemocionais como política pública em uma rede municipal de ensino. Com isso, as ações promovidas no Brasil pelo Instituto Ayrton Senna (IAS) poderão compor as diretrizes da Política de Educação Integral de um município catarinense. Nota-se, portanto, que o arcabouço jurídico cresce também nos entes subnacionais, em forma de lei, cuja abrangência é para a totalidade da rede de ensino. É possível, ainda, que ao incluir estas pautas nos municípios, conquistem-se mais aliados a fim de propor mudanças em propostas estaduais e mesmo nacional, uma vez que diversos municípios trabalham em rede e poderão pressionar as demais instâncias, indo ao encontro da proposição do IAS. O que inicialmente compunha apenas um projeto piloto, agora poderá se tornar diretriz de política pública, formatando a direção (conteúdo) da educação local.

Pesquisas como as de Adrião e Peroni (2011), Comerlatto (2013), Caetano (2013) apontam limitações nas políticas educacionais que mantêm parceria com OS. Destacam, dentre outros aspectos, o esvaziamento da gestão democrática, a impossibilidade de universalizar a educação básica e a implementação de formas gerenciais na gestão dos municípios pesquisados. 
Outro instrumento que caracteriza a relação público-privada são os termos de parcerias firmados entre o Poder Público e as Oscip, cuja lei de criação é a 9.790/1999 e alterações, contidas na Lei n⿳o 13.019/14, inclusive com nova redação no art. 1ํo o qual define o que são essas instituições, a saber,

Art. $1^{o}$ Podem qualificar-se como Organizações da Sociedade Civil de Interesse Público as pessoas jurídicas de direito privado sem fins lucrativos que tenham sido constituídas e se encontrem em funcionamento regular há, no mínimo, 3 (três) anos, desde que os respectivos objetivos sociais e normas estatutárias atendam aos requisitos instituídos por esta Lei.

Desse modo, a partir de 2014, a parceria entre o Poder Público e as Oscip só pode existir se esta possuir tempo mínimo de existência. Embora se assemelhe com as OS por serem instituições de direito privado sem fins lucrativos e que formam o Terceiro Setor, há distinção entre ambas. As Oscip têm direito ao título de entidade de utilidade pública e atuam numa área mais abrangente que as OS, ou seja, enquanto que as OS podem exercer atividades no campo do ensino, da pesquisa científica, desenvolvimento tecnológico e proteção e preservação do meio ambiente, cultura e saúde, a área de atuação das Oscip é vasta, podendo desempenhar serviços de combate à pobreza, cidadania e direitos humanos, promoção do voluntariado, dentre outros aspectos descritos no art. 3o da Lei n. 9790/1999.

Segundo Luz (2013, p. 90), “a Lei das Oscips reorientou não somente o papel do Estado frente às organizações do setor privado, como também redefiniu o formato de muitas organizações da sociedade civil com o Estado". Isso porque muitas instituições acabaram mudando sua orientação jurídica e ajustaram-se às normas vigentes na lei, "dirigindo suas ações em função das exigências do Terceiro Setor".

O Terceiro Setor não faz parte diretamente do Estado. Ao contrário, ele indiretamente transita no Estado por meio de ONG, institutos, fundações, associações, ou seja, uma série de organizações não lucrativas (público não estatal). Essas instituições evidenciam a capacidade de aumentar a governança do Estado, ou seja, "governar com efetividade e eficiência, voltando a ação dos serviços do Estado para o atendimento dos cidadãos" (DI PIETRO, 2015, p. 36).

As instituições do Terceiro Setor representam um "significativo papel político" (MONTAÑO, 2014, p. 54), pois materializam a concepção de seus propositores. Na maioria das vezes representam o setor privado, despreocupado com a democratização dos direitos sociais ou com a formação humana em uma perspectiva mais ampla, que não apenas para o domínio de ferramentas necessários ao mercado de trabalho.

O crescimento do ordenamento jurídico para regulamentação das OS - logo, do público não estatal -, vai ao encontro da afirmação de Bresser-Pereira (1998, p. 238). Dizia ele: "Tudo indica que no século vinte e um o público não-estatal (sic), seja como forma de propriedade e de produção de serviços sociais e científicos, seja como meio 
de controle social, terá um papel decisivo". A julgar pela reestruturação da legislação, é possível que o público não estatal já possa ser considerado fator fundamental para o desenvolvimento das políticas sociais.

De modo geral, analisamos até o momento os contratos de gestão e os termos de parcerias, que são os instrumentos que regulam as parcerias das OS e Oscip com a administração pública. Devido à promulgação da Lei no 13.019/2014, explanamos os termos de colaboração e de fomento, os quais foram criados para disciplinar de "forma mais rigorosa as parcerias com organizações da sociedade civil, em regime de mútua cooperação de finalidades de interesse público" (DI PIETRO, 2015, p. 289).

Concluída a exposição sobre os instrumentos que regulam a parceria da administração pública com as OS e Oscip, cabe destacar a Lei nº 11.079/2004, que institui normas gerais para licitação e contratação de Parcerias Público-Privadas (PPP) no âmbito da administração pública. Nessa lei, a parceria aparece como um contrato administrativo de concessão, na modalidade patrocinada ou administrativa (LUZ, 2013). Na modalidade patrocinada, a lei prevê tarifa paga pelo usuário, acrescida de contraprestação pecuniária do parceiro público ao privado (DI PIETRO, 2015).

No contrato administrativo, o objeto é a prestação de serviços de que a administração pública seja a usuária direta ou indireta. Nesse caso, não há, segundo Luz (2013) contraprestação pecuniária, já que existe o contrato de prestação de serviços, abrindo precedente para o financiamento total por parte do Estado de serviços prestados pela iniciativa privada, conforme já previsto na Lei no 8.987/1995 e Lei nº 9.074/1995.

Importante frisar que a legislação das PPP é mais específica para situações que envolvam valores vultosos, ou seja, acima de 20 milhões, dentre outras regras. No entanto, a lei que instituiu a PPP é mais uma das que solidificam a participação do setor privado no público, contribuindo para a terceirização.

A terceirização, em seu sentido amplo, abrange as formas pelas quais "se busca a diminuição do tamanho do Estado". Ela pode abranger, dentre outras formas a contratação de terceiros "em que a Administração Pública celebra ajustes de variados tipos para buscar a colaboração do setor privado [...]" (DI PIETRO, 2015, p. 217).

Exemplos destes ajustes são os contratos de prestação de serviços, instrumentos jurídicos que têm por objeto a execução de determinadas atividades complementares aos serviços, mediante remuneração pelos cofres públicos, a exemplo dos contratos firmados com as empresas fornecedoras de sistemas privados de ensino. A Lei nº 8.666/1993 determina que serviço "é toda atividade destinada a obter determinada utilidade de interesse para a Administração, como demolição, manutenção [...] ou trabalhos técnico-profissionais" (DI PIETRO, 2015, p. 233, grifo nosso). Nesse último serviço estão enquadrados os prestados pelos sistemas privados de ensino.

A participação do setor privado pode ocorrer somente de forma complementar (conforme art. 199 da CF), de modo a impedir que o contrato tenha por objeto o próprio 
serviço como um todo, em especial, nos serviços sociais, seja na área da saúde ou da educação. Não há, portanto, possibilidade de transferência ao privado da gestão operacional (DI PIETRO, 2015). Mesmo existindo a possibilidade de financiamento total do objeto contratado, o Poder Público não pode delegar a outrem o serviço na sua totalidade, pois o parceiro deve assumir somente a execução material de uma atividade prestada à administração pública.

Em se tratando de parcerias que resultem em contrato de prestação de serviços, seu objeto é apenas a gestão material da atividade, visto que a direção do serviço, ou seja, o que é designado por gestão estratégica pertence obrigatoriamente a uma pessoa pública, a quem cabe a última palavra quanto à escolha dos objetivos. Desse modo, quando há contrato de prestação de serviços, o prestador é um simples executor material, sendo que o Poder Público continua a ser o prestador direto do serviço e pode definir os objetivos a serem cumpridos na parceria.

No caso em tela, há que se considerar que os contratos de prestação de serviços firmados entre municípios e sistemas privados de ensino se caracterizam como uma forma de terceirização, pois existe contratação de terceiros. Por meio de processo licitatório (Lei 8.666/1993), o objeto da contratação é uma empresa privada, geralmente de fins lucrativos, que se torna responsável pela execução de determinadas atividades complementares ao serviço educacional, ou seja, pela execução material. A administração pública, mesmo pagando, tem sob sua responsabilidade a gestão desse serviço. Esse tipo de relação público-privada, mediada pela Lei de Licitações, é mais comum em pequenos municípios, visto não se enquadrarem na Lei das PPP.

Ao falar da terceirização na área da educação Di Pietro (2015, p. 235), lembra que quando prestada pelo Estado deve ser observado o princípio da gestão democrática no ensino público, "o que significa a participação do particular e não a transferência da gestão ao particular. Desse modo, se afasta a terceirização do serviço como um todo".

Em que pese ser no todo ou em parte, a terceirização existe a partir do conceito anteriormente explicitado. Isso abre espaços para novas possibilidades de fazer educação, tanto ideológicas como de ferramentas e que podem ou não estar afinados aos propósitos declarados pelos governantes e definidos nos planos educacionais.

Os contratos de prestação de serviços são instrumentos geralmente utilizados em parcerias com sistemas de ensino, que fornecem livros didáticos, assessorias pedagógicas para professores e gestores e ferramenta de gestão de resultados.

Procuramos assim, nesta última seção do artigo, suscitar uma reflexão que pudesse apontar a estruturação da relação público-privada na educação sob o ponto de vista de seus instrumentos. O conjunto de leis que se solidificaram a partir da reforma no final dos anos de 1990, articulou instrumentos legais que hoje oferecem legalidade aos procedimentos adotados nas parcerias entre a administração pública e o setor privado, ou 
seja, é por meio deles que as parcerias se efetivam. Legitimam, portanto, um conjunto de normas que levam à terceirização da educação.

\section{Considerações finais}

A construção das formas de regulação jurídica das parcerias entre o setor público e o privado nos serviços sociais ocorre por meio de diferentes instrumentos jurídicos, firmados para a execução de determinadas atividades de interesse público. A legislação relativa às organizações da sociedade civil tem recebido atenção especial por parte dos legisladores no País. Foram leis criadas logo após a reforma do Estado; outras foram aprovadas nos anos de 2014 e 2015. Se houve necessidade de criação de novas regras, é porque existe demanda de regulação, evidenciando o crescimento desse tipo de relação entre o Estado e o público não estatal, inclusive em municípios. Portanto, há uma base legal concisa em torno dessas parcerias, legitimando a interlocução do Poder Público com grupos do Terceiro Setor.

Não de menor expressão, a prestação de serviços à administração pública por parte de empresas privadas lucrativas também evidencia instrumentos jurídicos. Por meio de contratos de prestação de serviços, o setor privado lucrativo tem se colocado como parceiro das políticas sociais. Um exemplo dessa relação na educação é a venda de sistemas privados de ensino para redes públicas de ensino.

Em que pese nesse tipo de relação jurídica estabelecida o Poder Público possuir o direito à escolha das diretrizes da parceria, questionamos até que ponto a administração pública consegue ter clareza e firmeza para insistir na diretividade das ações que norteiam a relação público-privada. Mesmo que ela continue sendo a prestadora direta dos serviços, o executor material acaba não apenas por dar a direção, mas por estabelecer a concepção que norteará a prestação de serviço. É sobre esse aspecto que precisamos nos atentar e de fato analisar em que medida "alianças" com o setor privado não constituem "presentes de grego". Necessitamos questionar com que tipo de projeto educacional essas políticas estão comprometidas, visto primarem pela terceirização e imprimirem um modelo educativo para a educação pública que preza pela racionalização econômica, imposta pelo conceito de eficácia na NGP.

Por fim, observamos que a reforma foi fundamental para preparar o terreno conceitual das futuras regulamentações legais. No entanto, ela ampliou os espaços de atuação do setor privado, aproximando significativamente o mercado das redes de ensino, sendo que as próprias organizações passaram por mudanças no âmbito de sua estrutura, de modo a se adaptarem às exigências atuais do capitalismo. 


\section{Notas}

1 Pesquisa financiada pelo Programa de Bolsas Universitárias (UNIEDU/SC).

2 Reforma do Estado e reforma do aparelho do Estado. Segundo Di Pietro (2015) é necessário distingui-las. A primeira é um projeto mais amplo que diz respeito às várias áreas do governo e, ainda, do conjunto da sociedade brasileira. A segunda é restrita e está orientada para tornar a administração pública mais eficiente, sentido este que orienta o Plano Diretor da Reforma do Aparelho do Estado. Portanto, nesse trabalho, quando nos referimos à reforma, o fazemos considerando o segundo conceito.

3 Segundo Di Pietro (2015, p.14), o interesse público, sob o aspecto jurídico, reveste-se de um aspecto ideológico e passa a confundir-se com a ideia de bem comum. A nova roupagem do termo adquirida após o Estado Liberal humaniza-se à medida que passa a se preocupar não somente com os bens materiais, mas com os valores considerados essenciais à existência digna "e que exige a atuação do Estado para diminuir as desigualdades sociais e levar a toda a coletividade o bem-estar social".

4 A relação público-privada é um termo mais abrangente ao nos referirmos a quaisquer tipos de parcerias e seus diversos instrumentos.

5 O projeto de Lei Ordinária nº 106/2017 aprovada na Câmara de Vereadores de Chapecó (SC) em 23 de agosto de 2017, aguardando a sanção do executivo.

\section{Referências}

ADRIÃO, Theresa; PERONI, Vera. Análise das consequências de parceria firmadas entre municípios brasileiros e a Fundação Ayrton Senna para a oferta educacional. Relatório de Pesquisa, 2011. Disponível em: http://www.ufrgs.br/faced/peroni/docs/INSTITUTO\%20AYRTON\%20SENNA\%20 RELATORIO.pdf. Acesso em: 23 ago. 2016.

\section{BRASIL. Constituição da República Federativa do Brasil, 1988.}

. Lei no 9.637, de 15 de maio de 1998. Dispõe sobre a qualificação de entidades como organizações sociais, a criação do Programa Nacional de Publicização, a extinção dos órgãos e entidades que menciona e a absorção de suas atividades por organizações sociais.

Lei $\mathrm{n}^{\mathrm{0}}$ 9.790, de 23 de março de 1990. Dispõe sobre a qualificação de pessoas jurídicas de direito privado, sem fins lucrativos, como Organizações da Sociedade Civil de Interesse Público, institui e disciplina o Termo de Parceria.

Lei $\mathbf{n}^{\mathbf{0}} \mathbf{1 1 . 0 7 9}$, de 30 de dezembro de 2004. Institui normas gerais para licitação e contratação de parceria público-privada no âmbito da Administração Pública.

Lei $\mathrm{n}^{\mathbf{0}} \mathbf{1 3 . 0 1 9}$, de 31 de julho de 2014. Estabelece o regime jurídico das parcerias entre a Administração Pública e as organizações da sociedade civil.

. Lei n⿳0 13.204 , de 14 de dezembro de 2015.

BRESSER-PEREIRA, Luiz Carlos. Reforma do Estado para a cidadania: a reforma gerencial brasileira na perspectiva internacional. São Paulo: Editora 34; Brasília: ENAP, 1998. 
Estratégia e Estrutura para um novo Estado. Revista de Economia Política, vol. 17, n.3, p. 25-38, jul./set. 1997.

CAETANO, Maria Raquel. Relações entre o público e o privado e a parceria com o Instituto Ayrton Senna no projeto piloto de alfabetização no RS: implicações na gestão pedagógica. 2013. 303 f. Tese (Doutorado em Educação) - Universidade Federal do Rio Grande do Sul - UFRGS, 2013.

COMERLATTO, Luciani Paz. Implicações da parceria público-privada para gestão democrática na educação: um estudo baseado na parceria do IAS com a educação municipal de Joinville /SC. 2013. 265f. Tese (Doutorado em Educação) - Universidade Federal do Rio Grande do Sul - UFRGS, 2013.

DI PIETRO, Maria Sílvia. Parcerias na Administração Pública: concessão, permissão, franquia, terceirização público-privada e outras formas. 10 ed. Editora Atlas: São Paulo, 2015.

LOMBARDI, José Claudinei; JACOMELLI, Mara Regina; SILVA, Tânia Mara da. (orgs). O público e o privado na história da educação brasileira: concepções e práticas. Campinas: Autores Associados/ Histedbr, 2005.

LUZ, Lilian Xavier. Marco Legal do público e do privado na educação no contexto pós-reforma do Estado. In: ADRIÃO, Theresa; PERONI, Vera. Gestão Municipal da Educação e as Parcerias com o Instituto Ayrton Senna. Goiânia: Funape, 2013, p. 82-97.

MONTAÑO, C. O lugar histórico e o papel político das ONGs. In: MONTAÑO, C. (org.). O Canto da Sereia. Crítica à ideologia e aos projetos do "Terceiro Setor". São Paulo: Cortez, 2014, p. 53-95.

MUNICÍPIO DE CHAPECÓ. Câmara Municipal de Vereadores. Projeto de Lei Ordinária nº 106/2017. Disponível em: http://www.legislador.com.br/LegisladorWEB.ASP?WCI=ProjetoTexto\&ID=20\&INEspe cie=1\&nrProjeto=106\&aaProjeto=2017 Acesso em: 27 set. 2017.

ROBERTSON, Susan; VERGER, Antoni. A origem das parcerias público-privada na governança global da educação. Revista Educação e Sociedade. Campinas, v. 33, n. 121, p. 1133-1156, out./dez. 2012. 